\title{
Antifeedant effects of common terpenes from Mediterranean aromatic plants on Leptinotarsa decemlineata
}

\author{
Gonzalo Ortiz de Elguea-Culebras ${ }^{1,2}$, Raúl Sánchez-Vioque ${ }^{2,3 *}$, María Isabel Berruga1, David \\ Herraiz-Peñalver², Omar Santana-Méridas ${ }^{2,3}$
}

${ }^{1}$ Departamento de Ciencia y Tecnología Agroforestal y Genética, ETSIAM-IDR, Universidad de Castilla-La Mancha, Campus Universitario 02071, Albacete, Spain. ${ }^{2}$ Centro de Investigación Agroforestal de AlbaladejitoIRIAF, Carretera Toledo-Cuenca km 174, 16194 Cuenca, Spain. ${ }^{3}$ Instituto de Recursos Humanos para la Ciencia y la Tecnología (INCRECYT), Fundación Parque Cientifico y Tecnológico de Castilla-La Mancha, Paseo de la Innovación 1, 02006 Albacete, Spain. *Corresponding author: rsanchezv@jccm.es

\begin{abstract}
Essential oil terpenes are secondary metabolites produced in different biological pathways as pollinator attraction signals, but also as defense mechanisms against insect pests, herbivores, microorganisms, competing plants, etc. In this context, we have evaluated a total of 24 terpenes commonly found in Mediterranean aromatic plants, including 8 monoterpene hydrocarbons, 9 oxygenated monoterpenes, 2 esterified monoterpenes, 3 sesquiterpene hydrocarbons and 2 oxygenated sesquiterpenes in order to determine their antifeedant effects on the Colorado potato beetle (Leptinotarsa decemlineata Say), a major pest of potato crops. Terpene hydrocarbons showed low antifeedant activity, whereas the oxygenated sesquiterpene (-)- $\alpha$-bisabolol with an inhibition activity of $96.3 \%$ was the most active, followed by carvacrol $(90.9 \%),(+)$-Terpinen-4-ol $(87.1 \%)$ and thymol $(81.5 \%)$. Other terpenes like (1S)-(-)-verbenone (72.9\%), (+/-)-camphor $(63.4 \%)$ and linalyl acetate $(60.7 \%)$ showed moderate activity. Subsequently, terpenes showing antifeedant activity against this insect were also tested in allelopathic assays to determine potential damage to the crops. Results showed phytotoxic effects for $(1 S)-(-)$-verbenone on Lactuca sativa germination, and for carvacrol on both the seed germination and the leaf and root growth of Lolium perenne. In conclusion, (-)- $\alpha$-bisabolol is the best option to develop natural antifeedant formulations against $L$. decemlineata on the basis of its high antifeedant and low phytotoxic activities.
\end{abstract}

Keywords: Antifeedant activity, Leptinotarsa decemlineata, (-)- $\alpha$-bisabolol, (+)-Terpinen-4-ol, carvacrol 


\section{Introduction}

Leptinotarsa decemlineata Say (Coleoptera: Chrysimelidae) or the Colorado potato beetle is a common phytophagous insect that generates severe yield losses of potato crops along America, Europe and Asia. This pest is widely known for its high fertility rates and for its capability of developing fast resistances to traditional synthetic agrochemicals (Alyokhin et al., 2006; 2007). Thus, there is an increasing interest in new and safe agrochemicals to avoid resistance and minimize environmental issues. Essential oils (EOs) obtained from the distillation of aromatic and medicinal plants, have been considered as potential exploitable insecticides to control and repel different insects because of their low health and ecological risks (Tampe et al,. 2016; Isman, 2000). These EOs are complex mixtures of terpenes, which are secondary metabolites produced by aromatic plants involved, among others, in defense mechanisms against phytophagous pests, microorganism diseases, herbivore organisms, etc. The major terpenes found in EOs are the monoterpenes $\left(\mathrm{C}_{10}\right)$, but they also contain sesquiterpenes $\left(\mathrm{C}_{15}\right)$ or even traces of some diterpenes $\left(\mathrm{C}_{20}\right)$. These compounds are common in essential oils of different plants from diverse families including Asteraceae (Leonardi et al., 2013), Lamiaceae (Herraiz-Peñalver et al., 2015), Pinaceae (Sadeghi et al., 2013), Solanaceae (Murungi et al., 2013), etc. Additionally, recent studies have suggested that the addition of micronutrients and the inoculation of aromatic plants with mycorrhiza can enhance the production of different terpenes as well as other secondary metabolites, increasing the yield of biocidal compounds from natural sources (Yadegari, 2015; Jugran et al., 2015).

The chemical composition of the EO of each species depends on the population, variety, cultivar, ecotype, the organs from where they are produced, or even on the phenologic cycle (Herraiz-Peñalver et al., 2015).
Such variability may well reduce the possible resistance mechanisms of $L$. decemlineata but make rather difficult or even impossible to predict the bioactivity of EOs unless they are directly tested on the insect. In this sense, the individual assays of terpenes might indicate the potential insecticidal activity of EOs with a known chemical composition and facilitate the selection of chemotypes with a higher content of bioactive terpenes. Nonetheless, synergisms or antagonisms among plant compounds may respectively increase or reduce bioactivities, as previously observed for the flavonoid taxifolin on a multiple insecticide-resistant Colorado potato beetle strain (Wang et al., 2016). Besides, the synergistic effect of diverse terpenes on Culex quinquefasciatus Say has also been observed (Pavela, 2015). Consequently, these aspects should be considered by agrochemical industry when developing commercial biopesticides.

The aim of this work was to assay in choice test the antifeedant capacity of 24 common terpenes widely identified in essential oils of aromatic and medicinal plants from Mediterranean areas against the Colorado potato beetle. This information could be helpful in the selection of essential oils with higher ratios of active compounds and presumably, with a higher bioactivity against this pest. Subsequently, terpenes that showed significant antifeedant activity against $L$. decemlineata were also assayed for their phytotoxicity in order to identify potential damage to the plants.

\section{Materials and Methods}

\subsection{Terpene standards}

Acetone and terpenes including monoterpenes (hydrocarbons, oxygenated and esterified) and sesquiterpenes (hydrocarbons, oxygenated) were acquired 
from Sigma-Aldrich (St. Louis, MO, USA) (Table 1). AS 220/C/2, Radom, Poland) and dissolved in acetone Terpenes were weighed in a precision balance (Radwag $(5 \mu \mathrm{g} / \mu \mathrm{L})$ previous to the assays on the insects.

Table 1. Terpenes assayed for their antifeedant activities against Leptinotarsa decemlineata.

\begin{tabular}{|c|c|c|c|c|c|}
\hline Compounds tested & MF & MW (g/mol) & PubChem ID & Source & Purity \\
\hline \multicolumn{6}{|l|}{ Monoterpene hydrocarbons } \\
\hline$p$-cymene & $\mathrm{C}_{10} \mathrm{H}_{14}$ & 134.22 & 7463 & synthetic & $\geq 97.0 \%$ \\
\hline$(+)$-camphene & $\mathrm{C}_{10} \mathrm{H}_{16}$ & 136.23 & 92221 & synthetic & $\geq 90.0 \%$ \\
\hline (S)-(-)-limonene & $\mathrm{C}_{10} \mathrm{H}_{16}$ & 136.23 & 439250 & n.d. & $\geq 99.0 \%$ (sum of enantiomers) \\
\hline$(R)-(+)$-limonene & $\mathrm{C}_{10} \mathrm{H}_{16}$ & 136.23 & 440917 & n.d. & $\geq 99.0 \%$ (sum of enantiomers) \\
\hline Myrcene & $\mathrm{C}_{10} \mathrm{H}_{16}$ & 136.23 & 31253 & synthetic & $\geq 95.0 \%$ \\
\hline$(+/-)-\alpha$-pinene & $\mathrm{C}_{10} \mathrm{H}_{16}$ & 136.23 & 6654 & n.d. & $98.0 \%$ \\
\hline$(-)-\beta$-pinene & $\mathrm{C}_{10} \mathrm{H}_{16}$ & 136.23 & 440967 & n.d. & $99.0 \%$ \\
\hline$\gamma$-terpinene & $\mathrm{C}_{10} \mathrm{H}_{16}$ & 136.23 & 7461 & n.d. & $\geq 97.0 \%$ \\
\hline \multicolumn{6}{|l|}{ Oxygenated monoterpenes } \\
\hline Carvacrol & $\mathrm{C}_{10} \mathrm{H}_{14} \mathrm{O}$ & 150.22 & 10364 & synthetic & $\geq 98.0 \%$ \\
\hline Thymol & $\mathrm{C}_{10} \mathrm{H}_{14} \mathrm{O}$ & 150.22 & 6989 & n.d. & $\geq 99.0 \%$ \\
\hline$(1 S)$-(-)-verbenone & $\mathrm{C}_{10} \mathrm{H}_{14} \mathrm{O}$ & 150.22 & 92874 & synthetic & $\geq 93.0 \%$ \\
\hline (+/-)-camphor & $\mathrm{C}_{10} \mathrm{H}_{16} \mathrm{O}$ & 152.23 & 2537 & synthetic & $\geq 95.5 \%$ \\
\hline (-)-borneol & $\mathrm{C}_{10} \mathrm{H}_{18} \mathrm{O}$ & 154.25 & 439569 & n.d. & $97 \%$ (predominantly endo) \\
\hline Eucalyptol & $\mathrm{C}_{10} \mathrm{H}_{18} \mathrm{O}$ & 154.25 & 2758 & natural & $\geq 99.0 \%$ \\
\hline Linalool & $\mathrm{C}_{10} \mathrm{H}_{18} \mathrm{O}$ & 154.25 & 6549 & n.d. & $97.0 \%$ \\
\hline$(+)$-Terpinen-4-ol & $\mathrm{C}_{10} \mathrm{H}_{18} \mathrm{O}$ & 154.25 & 11230 & n.d. & pharmaceutical standard \\
\hline$\alpha$-terpineol & $\mathrm{C}_{10} \mathrm{H}_{18} \mathrm{O}$ & 154.25 & 17100 & n.d. & $90.0 \%$ \\
\hline \multicolumn{6}{|l|}{ Esterified monoterpenes } \\
\hline (-)-bornyl acetate & $\mathrm{C}_{12} \mathrm{H}_{20} \mathrm{O}_{2}$ & 196.29 & 93009 & n.d. & $95.0 \%$ \\
\hline Linalyl acetate & $\mathrm{C}_{12} \mathrm{H}_{20} \mathrm{O}_{2}$ & 196.29 & 8294 & synthetic & $\geq 97.0 \%$ \\
\hline \multicolumn{6}{|c|}{ Sesquiterpene hydrocarbons } \\
\hline$\beta$-caryophyllene & $\mathrm{C}_{15} \mathrm{H}_{24}$ & 204.35 & 5281515 & synthetic & $\geq 80.0 \%$ \\
\hline Farnesene & $\mathrm{C}_{15} \mathrm{H}_{24}$ & 204.35 & 5281516 & synthetic & mixture of isomers \\
\hline$(-)$ - $\alpha$-gurjunene & $\mathrm{C}_{15} \mathrm{H}_{24}$ & 204.35 & 15560276 & n.d. & $\geq 97.0 \%$ (sum of enantiomers) \\
\hline \multicolumn{6}{|l|}{ Oxygenated sesquiterpenes } \\
\hline Caryophyllene oxide & $\mathrm{C}_{15} \mathrm{H}_{24} \mathrm{O}$ & 220.35 & 14350 & synthetic & $95.0 \%$ \\
\hline (-)- $\alpha$-bisabolol & $\mathrm{C}_{15} \mathrm{H}_{26} \mathrm{O}$ & 222.37 & 442343 & n.d. & $\geq 93.0 \%$ \\
\hline
\end{tabular}

n.d.: not defined 


\subsection{Insect rearing}

Male and female adults of Leptinotarsa decemlineata Say (Coleoptera:Chrysomelidae) were collected in May 2016 from a natural untreated potato crop in Cuenca (Spain) and reared on potato foliage (Solanum tuberosum L.) in growth chambers at $22 \pm 1{ }^{\circ} \mathrm{C}$ and $>70 \%$ relative humidity, with a constant photoperiod of 16:8h (L:D). Potato plants were 6-7 weeks old (prior to flowering), about $25-30 \mathrm{~cm}$ high and cultivated with no plant treatments both at the crop fields of Centro de Investigación Agroforestal de Albaladejito (Cuenca, Spain) and in growth chambers as described above.

\subsection{In vitro antifeedant activity}

Feeding assays were tested in triplicate in choice tests with four male and female $L$. decemlineata individuals (Figure 1) as described in Rodilla et al. (2008). In six Petri dishes, containing 4 potato leaf disks $\left(1.0 \mathrm{~cm}^{2}\right)$ : 2 control (acetone) and 2 treated with the terpene at an initial dose of $50 \mu \mathrm{g} / \mathrm{cm}^{2}$. Experiments were performed in growth chambers $\left(22^{\circ} \mathrm{C}, 70 \% \mathrm{RH}, 16: 8 \mathrm{~L}: \mathrm{D}\right)$, and finished when insects fed at least $50 \%$ of control or treatment disks. Subsequently, non-consumed foliar areas were calculated by means of Image J Version 1.37 r, 2010 (http://rsb.info.nih.gov./ij/). The feeding inhibition capacity of each compound was calculated as follows: $\% \mathrm{FI}=[1-(\mathrm{T} / \mathrm{C})] \times 100$, where $\mathrm{T}$ and $\mathrm{C}$ were the non-consumed area of treatment or control disks, respectively. The effective concentration to obtain $50 \%\left(\mathrm{EC}_{50}\right)$ or $90 \%\left(\mathrm{EC}_{90}\right)$ feeding inhibition was calculated by statistical logarithmic regression.

\subsection{Allelopathic effects}

Terpenes were assayed with seeds of lettuce (Lactuca sativa L. var. Carrascoy, dicotyledonous) and English ryegrass (Lolium perenne L., monocotyledonous)
(Fitó; Barcelona, Spain, http://www.semillasfito. $\mathrm{com} /$ ) as described in Moiteiro et al. (2006). Four $2.5 \mathrm{~cm}$ diameter paper filters were treated either with $20 \mu \mathrm{L}$ of acetone (control) or with $20 \mu \mathrm{L}$ of the treatment $(5 \mu \mathrm{g}$ terpene $/ \mu \mathrm{L}$ acetone, $100 \mu \mathrm{g}$ of terpene per filter), and placed in 12-well plates (Falcon, San Jose, CA, USA). Then, 10 dry seeds of $L$. sativa or 10 one-day-hydrated seeds of $L$. perenne were respectively introduced per well, followed by 700 $\mu \mathrm{L}$ of distilled water. Finally, the plate was inserted inside plastic zipper bags, to avoid desiccation, and incubated in growth chambers $\left(22^{\circ} \mathrm{C}, 70 \% \mathrm{RH}, 16: 8\right.$ L:D). Germination was monitored each 24 hours up to a total of 7/10 days (L. sativa/ L. perenne). Twenty-five newly emerged seedlings roots of $L$. sativa or roots and leafs of $L$. perenne were measured by the Image J Version 1.37 r, 2010 (http://rsb.info.nih. gov./ij/). Phytotoxic effects (\%) were calculated as follows: $100-[(\mathrm{T} / \mathrm{C}) \times 100]$, where $\mathrm{T}$ and $\mathrm{C}$ were the number of germinated seeds or the length of roots/ leaves of the treated and control seeds, respectively.

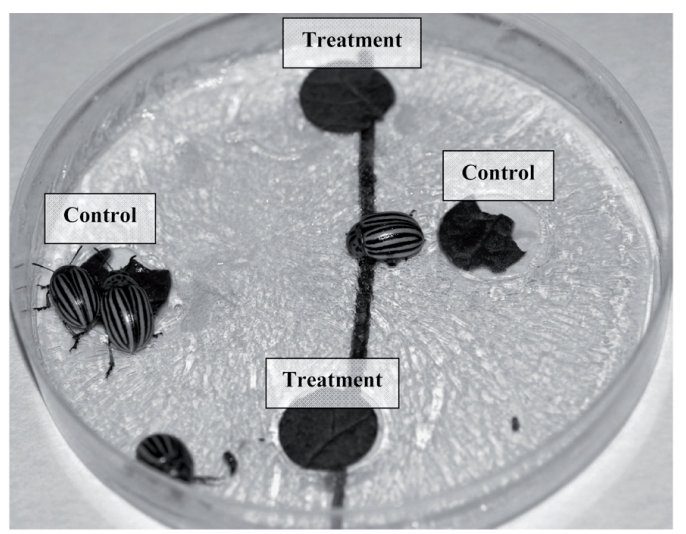

Figure 1. Choice feeding assay example. 


\subsection{Statistical analysis}

Logarithmic regression tests were carried out by means of the statistical software STATGRAPHICS Centurion XVI Version 16.1.18 (32-bits) (Statpoint Technologies, Inc., Herndon, VA, USA, 2010). Data were expressed as means \pm SE (Standard Error). The adjusted coefficient of determination $\left(\mathrm{R}_{2}\right)$ was determined from mean values in logarithmic regression tests. Additionally, $\mathrm{EC}_{50}$ and $\mathrm{EC}_{90}$ values along with their interval bilateral limits (lower and upper) were also predicted at $95 \%$ confidence level.

\section{Results}

\subsection{Antifeedant effects}

None of the monoterpene hydrocarbons demonstrated potential activity (FI $\leq 60 \%$ ) (Table 2 ). In contrast, five oxygenated monoterpenes presented antifeedant activity especially carvacrol and (+)-terpinen-4-ol, both showing inhibition percentages of around $90 \%$ at $50 \mu \mathrm{g} / \mathrm{cm}^{2}$. Thymol was also very effective (>80\%) whilst (-)-verbenone and camphor had a moderate activity, with percentages in the range of $60-75 \%$ at the same concentration. In the case of esterified monoterpenes, only linalyl acetate showed a moderate activity. Finally, the oxygenated sesquiterpene (-) $\alpha$-bisabolol was the terpene with the strongest activity against $L$. decemlineata, showing $\mathrm{EC}_{50}$ and $\mathrm{EC}_{90}$ values considerably lower than that of any other terpene. The chemical structures of active terpenes are represented in Figure 2.

\subsection{Allelopathic capacities}

As observed in Table 3, none of the terpenes that presented antifeedant activity against $L$. decemlineata showed noticeable phytotoxicity against the seeds of
L sativa. Germination was within normal ratios for all assayed terpenes, except for (-)-verbenone, that showed a total inhibition of the germination during the first $24 \mathrm{~h}$ although all the seeds germinated after $48 \mathrm{~h}$. On the contrary, the (+)-terpinen-4-ol showed a certain stimulant effect on the root development of $L$. sativa. Allelopathic assays on $L$. perenne seeds showed moderate negative effects for the carvacrol, as deduced from the inhibition of the germination of seeds $(26.8 \%)$ and a diminution on the development of root $(50.9 \%)$ and leaf $(60.8 \%)$. Finally, thymol $(33.0 \%)$ and (-)- $\alpha$-bisabolol (43.2\%) also presented certain negative effects on the normal development of L. perenne leaves.<smiles>Cc1ccc(C(C)C)cc1O</smiles>

(1) Carvacrol

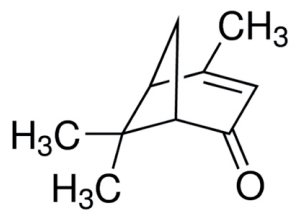

(3) (1S)-(-)-verbenone<smiles>Cc1ccc(C(C)C)c(O)c1</smiles>

(2) Thymol

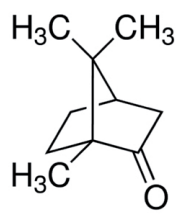

(4) (+/-)-camphor

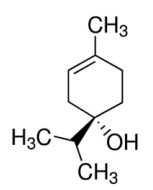

(5) (+)-Terpinen-4-o<smiles>C=CC(C)(CCC=C(C)C)OC(C)=O</smiles>

(6) Linalyl acetate<smiles>CC(C)=CCC[C@H](C)[C@H]1CC=C(C)CC1</smiles>

(7) (-)-- - -bisabolol

Figure 2. Molecular structures of antifeedant terpenes against adults of Leptinotarsa decemlineata (Source: www.sigmaaldrich.com) 
Table 2. Feeding inhibition percentages of twenty four terpenes against adults of Leptinotarsa decemlineata.

\begin{tabular}{|c|c|c|c|c|c|}
\hline Treatments & Dose $\left(\mu \mathrm{g} / \mathrm{cm}^{2}\right)$ & $\% \mathbf{F I}^{\mathbf{a}}$ & $R^{2}(\%)^{b}$ & $\mathrm{EC}_{50}$ (Limits) $^{\mathrm{c}}$ & $\mathrm{EC}_{90}$ (Limits) $^{\mathrm{d}}$ \\
\hline \multicolumn{6}{|c|}{ Monoterpene hydrocarbons } \\
\hline$p$-cymene & 50.0 & $44.60 \pm 10.6$ & n.d. & n.d. & n.d. \\
\hline$(+)$-camphene & 50.0 & $37.28 \pm 9.1$ & n.d. & n.d. & n.d. \\
\hline$(S)$-(-)-limonene & 50.0 & $50.87 \pm 12.2$ & n.d. & $\approx 50$ & n.d. \\
\hline$(R)-(+)$-limonene & 50.0 & $38.45 \pm 10.0$ & n.d. & n.d. & n.d. \\
\hline Myrcene & 50.0 & $35.57 \pm 11.0$ & n.d. & n.d. & n.d. \\
\hline$(+/-)$ - $\alpha$-pinene & 50.0 & $51.66 \pm 10.4$ & n.d. & $\approx 50$ & n.d. \\
\hline$(-)-\beta$-pinene & 50.0 & $33.70 \pm 12.3$ & n.d. & n.d. & n.d. \\
\hline$\gamma$-terpinene & 50.0 & $18.62 \pm 10.7$ & n.d. & n.d. & n.d. \\
\hline \multicolumn{6}{|c|}{ Oxygenated monoterpenes } \\
\hline \multirow[t]{4}{*}{ Carvacrol } & 50.0 & $90.92 \pm 7.2$ & 95.20 & $6.64(1.4-11.3)$ & $49.36(28.8-255.5)$ \\
\hline & 25.0 & $79.62 \pm 10.1$ & & & \\
\hline & 12.5 & $67.35 \pm 9.4$ & & & \\
\hline & 6.3 & $44.73 \pm 10.5$ & & & \\
\hline \multirow[t]{4}{*}{ Thymol } & 50.0 & $81.54 \pm 7.6$ & 92.75 & $10.76(4.3-16.8)$ & n.d. \\
\hline & 25.0 & $73.58 \pm 9.5$ & & & \\
\hline & 12.5 & $57.52 \pm 12.2$ & & & \\
\hline & 6.3 & $33.66 \pm 11.0$ & & & \\
\hline \multirow[t]{3}{*}{$(1 S)$-(-)-verbenone } & 50.0 & $72.90 \pm 9.7$ & 99.77 & $25.41(15.2-38.6)$ & n.d. \\
\hline & 25.0 & $50.41 \pm 11.9$ & & & \\
\hline & 12.5 & $25.10 \pm 10.5$ & & & \\
\hline \multirow[t]{3}{*}{$(+/-)$-camphor } & 50.0 & $63.36 \pm 11.5$ & 98.35 & $25.17(12.2-42.6)$ & n.d. \\
\hline & 25.0 & $48.68 \pm 10.9$ & & & \\
\hline & 12.5 & $38.01 \pm 10.2$ & & & \\
\hline (-)-borneol & 50.0 & $21.15 \pm 6.6$ & n.d. & n.d. & n.d. \\
\hline Eucalyptol & 50.0 & $46.98 \pm 9.2$ & n.d. & n.d. & n.d. \\
\hline Linalool & 50.0 & $41.70 \pm 12.2$ & n.d. & n.d. & n.d. \\
\hline \multirow[t]{4}{*}{$(+)$-Terpinen-4-ol } & 50.0 & $87.08 \pm 5.0$ & 98.06 & $10.31(4.4-15.9)$ & $52.66(30.9-221.9)$ \\
\hline & 25.0 & $74.44 \pm 8.8$ & & & \\
\hline & 12.5 & $57.00 \pm 13.0$ & & & \\
\hline & 6.3 & $35.79 \pm 12.1$ & & & \\
\hline$\alpha$-terpineol & 50.0 & $39.97 \pm 10.9$ & n.d. & n.d. & n.d. \\
\hline \multicolumn{6}{|l|}{ Esterified monoterpenes } \\
\hline (-)-bornyl acetate & 50.0 & $29.00 \pm 11.5$ & n.d. & n.d. & n.d. \\
\hline \multirow[t]{2}{*}{ Linalyl acetate } & 50.0 & $60.65 \pm 10.2$ & n.d. & $40.14(19.6-302.8)$ & n.d. \\
\hline & 25.0 & $27.05 \pm 11.5$ & & & \\
\hline \multicolumn{6}{|c|}{ Sesquiterpene hydrocarbons } \\
\hline$\beta$-caryophyllene & 50.0 & $34.70 \pm 12.2$ & n.d. & n.d. & n.d. \\
\hline Farnesene & 50.0 & $46.56 \pm 13.0$ & n.d. & n.d. & n.d. \\
\hline$(-)$ - $\alpha$-guriunene & 50.0 & $36.57 \pm 12.2$ & n.d. & n.d. & n.d. \\
\hline \multicolumn{6}{|c|}{ Oxygenated sesquiterpenes } \\
\hline Caryophyllene oxide & 50.0 & $30.71 \pm 7.3$ & n.d. & n.d. & n.d. \\
\hline \multirow[t]{7}{*}{ (-)- $\alpha$-bisabolol } & 50.0 & $96.25 \pm 1.9$ & 95.44 & $0.94(0.5-1.5)$ & $24.58(10-70.5)$ \\
\hline & 25.0 & $91.11 \pm 7.8$ & & & \\
\hline & 12.5 & $87.02 \pm 8.2$ & & & \\
\hline & 6.3 & $69.30 \pm 13.5$ & & & \\
\hline & 3.1 & $67.48 \pm 11.3$ & & & \\
\hline & 1.6 & $51.84 \pm 11.3$ & & & \\
\hline & 0.8 & $49.71 \pm 11.1$ & & & \\
\hline
\end{tabular}


Table 3. Phytotoxic effects of the antifeedant terpenes at $100 \mu \mathrm{g} / \mathrm{well}$.

\begin{tabular}{|c|c|c|c|c|c|c|c|c|c|}
\hline & \multicolumn{2}{|c|}{$\% \mathrm{GI}^{\mathrm{a}} \pm \mathrm{SE}$} & \multirow{2}{*}{$\frac{\%^{2} I^{b} \pm S E}{\text { Root }}$} & \multirow[b]{2}{*}{$72 \mathrm{~h}$} & \multicolumn{3}{|c|}{$\% \mathrm{GI}^{\mathrm{a}} \pm \mathrm{SE}$} & \multicolumn{2}{|c|}{$\% \mathrm{LI}^{\mathrm{b}} \pm \mathrm{SE}$} \\
\hline & $24 \mathrm{~h}$ & $48 \mathrm{~h}$ & & & $120 \mathrm{~h}$ & $168 \mathrm{~h}$ & $240 \mathrm{~h}$ & Root & Leaf \\
\hline \multicolumn{10}{|c|}{ Oxygenated monoterpenes } \\
\hline Carvacrol & $0.00 \pm 0.0$ & $0.00 \pm 0.0$ & $-17.03 \pm 7.5^{\mathrm{c}}$ & $80.49 \pm 8.1$ & $64.29 \pm 4.4$ & $53.85 \pm 8.5$ & $26.76 \pm 4.0$ & $50.94 \pm 9.9$ & $60.78 \pm 8.7$ \\
\hline Thymol & $10.00 \pm 5.5$ & $0.00 \pm 0.0$ & $-3.48 \pm 9.5$ & $39.02 \pm 11.0$ & $16.07 \pm 11.9$ & $7.69 \pm 9.5$ & $2.82 \pm 9.8$ & $20.95 \pm 15.0$ & $33.02 \pm 11.7$ \\
\hline$(I S)-(-)$-Verbenone & $100.00 \pm 0.0$ & $0.00 \pm 0.0$ & $2.59 \pm 5.4$ & $21.95 \pm 17.5$ & $10.71 \pm 18.1$ & $4.62 \pm 12.8$ & $-1.41 \pm 9.3$ & $4.19 \pm 17.6$ & $21.19 \pm 12.8$ \\
\hline$(+/-)$-Camphor & $0.00 \pm 0.0$ & $0.00 \pm 0.0$ & $-5.56 \pm 5.2$ & $19.51 \pm 11.0$ & $1.79 \pm 13.9$ & $6.15 \pm 7.8$ & $5.63 \pm 5.8$ & $-11.58 \pm 15.6$ & $-11.87 \pm 15.2$ \\
\hline$(+)$-Terpinen-4-ol & $0.00 \pm 0.0$ & $0.00 \pm 0.0$ & $-28.78 \pm 9.0$ & $31.71 \pm 15.3$ & $7.14 \pm 23.2$ & $-4.62 \pm 15.4$ & $-4.23 \pm 7.8$ & $6.30 \pm 15.4$ & $12.48 \pm 14.1$ \\
\hline \multicolumn{10}{|c|}{ Esterified monoterpenes } \\
\hline Linalyl acetate & $0.00 \pm 0.0$ & $0.00 \pm 0.0$ & $-11.53 \pm 7.0$ & $12.20 \pm 16.8$ & $-7.14 \pm 18.1$ & $-7.69 \pm 11.4$ & $-1.41 \pm 11.3$ & $5.70 \pm 17.7$ & $-4.30 \pm 19.6$ \\
\hline \multicolumn{10}{|c|}{ Oxygenated sesquiterpenes } \\
\hline$\alpha$-bisabolol & $7.50 \pm 6.5$ & $0.00 \pm 0.0$ & $-8.19 \pm 7.8$ & $19.51 \pm 14.5$ & $23.21 \pm 13.2$ & $13.85 \pm 12.3$ & $11.27 \pm 10.4$ & $17.38 \pm 9.3$ & $43.17 \pm 6.5$ \\
\hline
\end{tabular}

a $\% \mathrm{G}$ : Germination Inhibition percentage; b \%L: Length Inhibition percentage; ${ }^{\mathrm{c}}$ negative values indicate stimulant effects.

\section{Discussion}

\subsection{Insecticidal activity}

The antifeedant activity of the terpenes $\alpha$-pinene, $\beta$-pinene, eucalyptol, $\beta$-caryophyllene and caryophyllene oxide against $L$. decemlineata have been previously investigated by Rodilla et al. (2008). Among them, $\beta$-caryophyllene and caryophyllene oxide showed high antifeedant activities in contrast to the low percentages that we have observed for these compounds. The activities reported in this study for $\beta$-pinene and $\alpha$-pinene were also higher as compared with our data, whereas the activity of eucalyptol was similar in both works. Kostić et al. (2007) observed a moderate activity of camphor against $L$. decemlineata adults and larvae comparable to our results. These differences among studies might be related to the potential developing resistance of $L$. decemlineata against certain compounds, as previously reported (Alyokhin et al., 2006; 2007). In agreement with our results, the antifeedant activity of some terpene standards has been also demonstrated against other beetles. Thus, Yildirim et al. (2013) observed a high activity for terpinen-4-ol against Sitophilus zeamais (Coleoptera: Curculionidae). Furthermore, Kim et al. (2010) assayed the antifeedant activities of different terpenes against the beetle Tribolium castaneum (Coleoptera: Tenebrionidae) and concluded that caryophyllene oxide, thymol, $\alpha$-pinene, carvacrol and myrcene were the most active, whereas $\gamma$-terpinene, $p$-cymene, camphene and linalool present low activities, which is in part consistent with our results on L. decemlineata. The strong insecticidal effects of hymol and carvacrol on Alphitobius diaperinus (Coleoptera: Tenebrionidae) have also been reported by Szczepanik et al. (2012), and Erler (2005) demonstrated the high activity of carvacrol, $\gamma$-terpinene, thymol and terpinen-4-ol against the beetle Tribolium confusum (Coleoptera: Tenebrionidae) and the moth Ephestia kuehniella (Lepidoptera: Pyralidae). In addition, Gillette et al. (2014) proposed an effective mixture containing, among others, verbenone to avoid attacks from mountain pine beetles Dendroctonus ponderosae (Coleoptera: Curculionidae) on whitebark and limber pines. Summarizing, the above mentioned works are in agreement with the high antifeedant activities that we have observed for carvacrol, thymol and (+)-terpinen4-ol against $L$. decemlineata.

To our knowledge, there are not previous works on the antifeedant activity of $\alpha$-bisabolol against the Colorado potato beetle or other related beetles. However, some authors have searched for essential oils with a high content in this terpene due to its potential activity on different insects. Thus, Vila et al. (2010) propose the essential oil of Morella parvifolia (60\% $\alpha$-bisabolol) as a possible source of this compound, and De Andrade et al. (2004) reported a total $\alpha$-bisabolol content of $90 \%$ in the heartwood essential 
oil of a natural Brazilian population of Vanillosmopsis pohlii, which showed strong insecticidal effects against the silverleaf whitefly Bemisia argentifolii (Hemiptera: Aleyrodidae). Likewise, Kamatou and Viljoen (2010) have reviewed several aromatic plants with a high content in this compound including Eremanthus erythropappus, Smyrniopsis aucheri and Salvia runcinata. In addition, a possible larvicidal activity of the essential oil of Plinia cerrocampanensis against the yellow fever mosquito Aedes aegypti (Dpitera: Culicidae) has been related to this compound since it is the major component of the oil (Vila et al., 2010). Salamon et al. (2016) have suggested different breeding programs to develop German chamomile (Chamomila recutita) with a high content in 1-1- $\alpha$-bisabolol as it is an important indicator of flower quality and value for cosmetic and pharmaceutical industry.

\subsection{Phytotoxicity}

The phytotoxic effects of essential oils and their individual components on different weeds, have been reviewed by Amri et al. (2013) who conclude that thymol and carvacrol present a high activity. For example, Azirak and Karaman (2008) observed that these terpenes present a high phytotoxicity against different weeds, whereas Vokou et al. (2003) have demonstrated moderate negative effects for these terpenes and no effect for linalyl acetate against $L$. sativa, as also observed in our study. Nevertheless, the above study also shows exceptional phytotoxicities for the (+)-terpinen-4-ol and camphor against L. sativa, which is in contradiction with our results. From the screening of twenty seven monoterpenes, including carvacrol, thymol, camphor and linalyl acetate, De Martino et al. (2010) have observed that high concentrations of camphor affected the germination and growth of Raphanus sativus and the growth of Lepidium sativum. They also observed an inhibition of both the germination and growth of L. sativum seeds in the presence of high concentrations of thymol. As far as we know, no previous studies have been carried out on the phytotoxicity of verbenone and $\alpha$-bisabolol. In general, carvacrol was the most detrimental terpene to seeds although its phytotoxicity could be reduced if it is used in synergism with other non-phytotoxic antifeedant compounds. Therefore, the use of these antifeedant terpenes is justified according to their moderate to low negative effects on germination and development of these model plants.

\section{Conclusions}

This work demonstrates that certain oxygenated terpenes present in essential oils are endowed of insecticidal activities against $L$. decemlineata, as previously observed for other insects. From the screening of a total of 24 terpenes, including monoterpenes (hydrocarbons, oxygenated and esterified) and sesquiterpenes (hydrocarbons, oxygenated), we can conclude that (-)- $\alpha$-bisabolol, carvacrol, (+)-terpinen-4-ol and thymol were the most active against this pest, whereas (-)-verbenone, camphor and linalyl acetate presented certain antifeedant activities with inhibition percentages slightly above $60 \%$. The allelopathic tests showed that only (-)-verbenone had negative effects on the germination of Lactuca sativa seeds after 24 hours of incubation, and carvacrol on the seed germination and on the leaf and root growth of Lolium perenne. Consequently, the use of carvacrol as antifeedant in potato crops should be considered with caution since it could affect the plant development. Nevertheless, carvacrol has been assayed on standard target seeds selected for the study of allelopathy capacities, so a study directly on potato plants is necessary to clarify this point. Thymol and $\alpha$-bisabolol also presented moderate negative effects on the normal development of L. perenne leaves, whereas (+)-terpinen-4-ol was not 
phytotoxic. However, the antifeedant activity $\left(\mathrm{EC}_{50}\right)$ of $\alpha$-bisabolol was around 10 times stronger than that of (+)-terpinen-4-ol. In addition, the low toxicity of (-)- $\alpha$-bisabolol to humans has been certified by the Food and Drug Administration (FDA, 2015) who has granted this compound with Generally Regarded As Safe (GRAS) and by the Cosmetic Ingredient Review (CIR) Expert Panel (Andersen, 1999). Consequently, $\alpha$-bisabolol is the best option to develop natural antifeedant formulations against $L$. decemlineata on the basis of the high antifeedant and low phytotoxic activities of this terpene.

\section{Acknowledgements}

The research leading to these results has been financially supported by the Instituto Nacional de Investigaciones Agrarias (INIA, http://inia.es) with the projects RTA2012-00057-C03-03 and RTA2013-0000500-00. Ortiz de Elguea-Culebras also thanks to the Consejería de Educación, Cultura y Deportes (Junta de Comunidades de Castilla-La Mancha) for additional funding. We are really grateful to Alejandro Calvo López and Jesús Serrano Jiménez for their assistance.

\section{References}

Alyokhin, A., Dively, G., Patterson, M., Castaldo, C., Rogers, D., Mahoney, M., Wollam, J. 2007. Resistance and cross-resistance to imidacloprid and thiamethoxam in the Colorado potato beetle Leptinotarsa decemlineata. Pest Manag. Sci. 63(1), 32-41.

Alyokhin, A., Dively, G., Patterson, M., Mahoney, M., Rogers, D., Wollam, J. 2006. Susceptibility of imidacloprid-resistant Colorado potato beetles to non-neonicotinoid insecticides in the laboratory and field trials. Am. J. Potato Res. 83(6), 485-494.
Amri, I., Hamrouni, L., Hanana, M., Jamoussi, B. 2013. Review on the phytotoxic effects of essential oils and their individual components: News approach for weed management. Int. J. Appl. Biol. Pharm. 4(1), 96-114.

Andersen, F.A. 1999. Final report on the safety assesment of bisabolol. Int. J. Toxicol. 18(3), 33-40.

Azirak, S., Karaman, S. 2008. Allelopathic effect of some essential oils and components on the germination of weed species. Acta Agric. Scand. 51, 88-92.

De Andrade, I.L., Bezerra, J.N.S., Lima, M.A.A., De Faria, R.A.P.G., Lima, M.A.S., Andrade-Neto, M., Cavalcanti, F.S., Mesquita, A.L.M. 2004. Chemical composition and insecticidal activity of essential oils from Vanillosmopsis pohlii baker against Bemisia argentifolii. J. Agric. Food Chem. 52(19), 5879-5881.

De Martino, L., Mancini, E., Rolim de Almeida, L.F., De Feo, V. 2010. The antigerminative activity of twenty-seven monoterpenes. Molecules. 15, 6630-6637.

Erler, F. 2005. Fumigant activity of six monoterpenoids from aromatic plants in Turkey against the two stored-product pests confused flour beetle, Tribolium confusum, and Mediterranean flour moth, Ephestia kuehniella. Z. Pflanzenkr. Pflanzenschutz. 112(6), 602-611.

Gillette, N. E., Kegley, S.J., Costello, S.L., Mori, S.R., Webster, J.N., Mehmel, C.J., Wood, D.L. 2014. Efficacy of verbenone and green leaf volatiles for protecting whitebark and limber pines from attack by mountain pine beetle (Coleoptera: Curculionidae: Scolytinae). Environ. Entomol. 43(4), 1019-1026.

Herraiz-Peñalver, D., Ortiz De Elguea-Culebras, G., Sánchez-Vioque, R., Santana Méridas, O. 2015. Identification of a hybrid species of sage (Salvia officinalis L. x S. lavandulifolia subsp. lavandulifolia) through 
the study of the essential oil. J. of Essent. Oil Res. 27(5), 363-372.

Image J Version 1.37 r. 2010. (http://rsb.info.nih. gov./ij/).

Isman, M.B. 2000. Plant essential oils for pest and disease management. Crop Prot. 19, 603-608.

Jugran, A.K., Bahukhandi, A. Dhyani, P., Bhatt, I.D., Rawal, R.S., Nandi, S.K., Palni, L.M.S. 2015. The effect of inoculation with mycorrhiza: AM on growht, phenolics, tannins, phenolic composition and antioxidant activity in Valeriana jatamansi Jones. J. Soil Sci. Plant Nutr. 15 (4), 1036-1049.

Kamatou, G.P.P., Viljoen, A.M. 2010. A review of the application and pharmacological properties of $\alpha$-bisabolol and $\alpha$-bisabolol-rich oils. JACS. 87(1), 1-7.

Kim, S.I., Yoon, J.S., Jung, J.W., Hong, K.B., Ahn, Y.J., Kwon, H.W. 2010. Toxicity and repellency of origanum essential oil and its components against Tribolium castaneum (Coleoptera: Tenebrionidae) adults. J. Asia Pac. Entomol. 13(4), 369-373.

Kostić, M., Dražić, S., Popović, Z., Stanković, S., Sivčev, I., Živanović, T. 2007. Developmental and feeding alternations in Leptinotarsa decemlineata say. (Coleoptera: Hrysomelidae) caused by Salvia officinalis L. (Lamiaceae) essential oil. Biotechnol. Biotechnol. Equip. 21(4), 426-430.

Leonardi, M. Ambryszewska, K.E., Melai, B., Flamini, G., Cioni, P.L., Parri, F., Pistelli, L. 2013. Essential-oil composition of Helichrysum italicum (Roth) G. DON ssp. Italicum from Elba Island (Tuscany, Italy). Chem Biodivers. 10, 343-355.

Moiteiro, C., Joao, M., Curto, O.M. Mohamed, N., Bailen, M., Martínez-Díaz, R., González-Coloma, A. 2006. Biovalorization of friedelane triterpenes derived from cork processing industry byproducts. J. Agric. Food Chem. 54, 3566-3571.
Murungi, L.K., Kirwa, H., Torto, B. 2013. Differences in essential oil content of berries and leaves of Solanum sarrachoides (Solanaceae) and the effects on oviposition of the tomato spider mite (Tetranychus evansi). Ind. Crop. Prod. 46, 73-79.

Pavela, R. 2015. Acute toxicity and synergistic and antagonistic effects of the aromatic compounds of some essential oils against Culex quinquefasciatus Say larvae. Parasitol. Res. 114(10), 38353853 .

Rodilla, J.M., Tinoco, M.T., Morais, J.C., Gimenez, C., Cabrera, R., Martín-Benito, D., Castillo, L,. Gonzalez-Coloma, A. 2008. Laurus novocanariensis essential oil: Seasonal variation and valorization. Biochem. Syst. Ecol. 36(3), 167-176.

Sadeghi, H., Tahery, Y., Moradi, S. 2013. Intra- and inter-specific variation of turpentine composition in Eldar pine (Pinus eldarica Medw.) and black pine (Pinus nigra Arnold). Biochem. Syst. Ecol. 48, 189-193.

Salamon, I., Fejer, J., Grulova, D. 2016. Breeding of German chamomile, Chamomila recutita L., with the highest content of /-/- $\alpha$-bisabolol. ACS Symp. Ser. 2118, 209-234.

Szczepanik, M., Zawitowska, B., Szumny, A. 2012. Insecticidal activities of Thymus vulgaris essential oil and its components (thymol and carvacrol) against larvae of lesser mealworm, Alphitobius diaperinus Panzer (Coleoptera: Tenebrionidae). Allelopathy J, 30(1), 129-142.

Tampe, J., Parra, L., Huaiquil, K., Quiroz, A. 2016. Potential repellent activity of the essential oil of Ruta chalepensis (Linnaeus) from Chile against Aegorhinus superciliosus (Guérin) (Coleoptera: Curculionidae). J. Soil Sci. Plant Nutr. 16(1), 48-59.

Vila, R., Santana, A.I., Pérez-Rosés, R., Valderrama, A., Castelli, M.V., Mendonca, S., Zacchino. S., Gupta, M.P., Cañigueral, S. 2010. Composition 
and biological activity of the essential oil from leaves of Plinia cerrocampanensis, a new source of $\alpha$-bisabolol. Bioresour. Technol. 101(7), 25102514.

Vokou, D., Douvli, P., Blionis, G.J., Halley, J.M. 2003. Effects of monoterpenoids, acting alone or in pairs, on seed germination and subsequent seedling growth. J. Chem. Ecol. 29(10), 2281-2301.

Wang, Z., Zhao, Z., Cheng, X., Liu, S., Wei, Q., Scott, I.M. 2016. Conifer flavonoid compounds inhibit detoxification enzymes and synergize insecticides. Pest. Biochem. Physiol. 127, 1-7.
Yadegari, M. 2015. Foliar application of micronutrients on essential oils of borago, thyme and marigold. J. Soil Sci. Plant Nutr. 15(4), 949-964.

Yildirim, E., Emsen, B., Kordali, S. 2013. Insecticidal effects of monoterpenes on Sitophilus zeamais Motschulsky (Coleoptera: Curculionidae). J. Appl. Bot. Food Qual. 86(1), 198-204. 